\title{
Estimation of areal precipitation for runoff modelling using wind data: a case study in Sweden
}

\author{
Barbro Johansson ${ }^{1, *}$, Deliang Chen ${ }^{2,3}$ \\ ${ }^{1}$ Swedish Meteorological and Hydrological Institute, 60176 Norrköping, Sweden \\ ${ }^{2}$ Earth Sciences Centre, Göteborg University, Box 460, 40530 Göteborg, Sweden \\ ${ }^{3}$ Laboratory for Climate Studies/National Climate Center, China Meteorological Administration, 100081 Beijing, China
}

\begin{abstract}
In mountainous regions, rainfall distribution is influenced by topography in combination with wind speed and direction. This has implications for estimates of catchment precipitation as input to hydrological models. The objective of this work was to investigate if wind information can be used to improve the accuracy of precipitation estimates, particularly for operational applications. A geostrophic wind, computed from pressure observations, was assumed to represent the airflow at an altitude relevant for precipitation distribution. Interpolated values of precipitation (optimal interpolation) were verified directly against point observations. In some mountainous catchments with low annual evapotranspiration, estimates of long-term mean areal precipitation could be verified through the water balance equation. The effects of the interpolations with and without wind information on the performance of a rainfall-runoff model were also investigated. There were 2 main factors in favour of using wind information in the interpolation: (1) a better description of the seasonal distribution; and (2) a lower sensitivity to reductions in the number of meteorological stations.
\end{abstract}

KEY WORDS: Areal precipitation - Orographic enhancement - Interpolation - Rainfall-runoff modelling $\cdot$ Spatial distribution $\cdot$ Airflow $\cdot$ Sweden

\section{INTRODUCTION}

Accurate estimates of catchment precipitation are essential in many hydrological applications. They are particularly difficult to achieve in mountainous regions, where precipitation gradients are complex and meteorological networks sparse. Ground radar measurements provide areal coverage but are problematic in mountainous terrain due to blocking of the radar beam. Point observations cannot fully represent the spatial variation, especially as stations are often located in valleys. Supplementary information is thus required. A common practice has been to relate precipitation directly to elevation (e.g. Lindström et al. 1997, Goovaerts 2000). Such relationships vary considerably between regions and are thus best applied locally in areas with similar exposure, e.g. the windward side of a mountain (Phillips et al. 1992, Daly et al. 1994). Statistical studies over larger areas have shown that other factors can be more important (Shermerhorn 1967, Blumer \& Lang 1993, Basist et al. 1994, Konrad 1996, Prudhomme \& Reed 1998), such as the slope in the prevailing wind direction, the station exposure or proximity to blocking barriers, the bumpiness of the surrounding terrain and the distance to the sea.

Precipitation-elevation relationships also vary with precipitation events. As most hydrological models operate on time scales of $1 \mathrm{~d}$ or less, this needs to be accounted for. Garen et al. (1994) tackled the problem by defining the precipitation-elevation relationship for a limited period (typically 1 to $4 \mathrm{wk}$ ) around each precipitation event. Bastin et al. (1984) presented a method for estimation of the kriging variogram, dependent on season and rainfall intensity. A comprehensive review of the different factors influencing precipitation distribution in mountainous terrain is given by Smith (1979). The mechanisms are complex and affected by the weather type and the size of the mountains. A full 
description requires a model of great complexity. In a case study in Sweden, Johansson \& Chen (2003) used a simple statistical approach to define typical precipitation patterns as a function of wind speed and wind direction. They concluded that the statistical relationship is useful in describing the main factors governing the spatial distribution of precipitation in Sweden under specific wind conditions.

Operational runoff modelling has been carried out in Sweden since the mid-1970s (Bergström 1995). The increasing number of applications has led to a need to develop computerised and consistent interpolation schemes for estimating daily catchment precipitation. It has been assumed that the most accurate estimates could be achieved by combining point observations with informa-
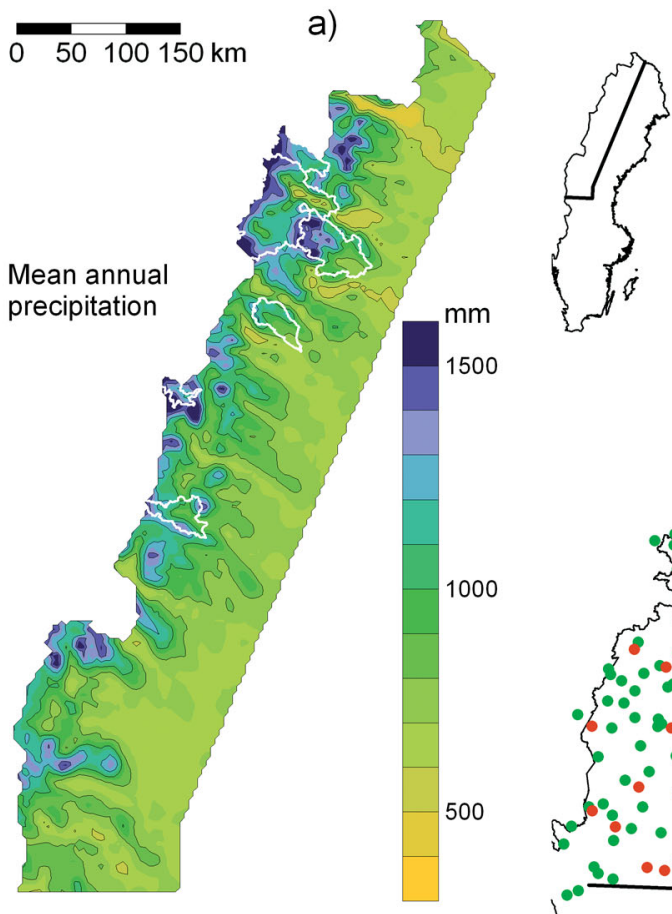

b)

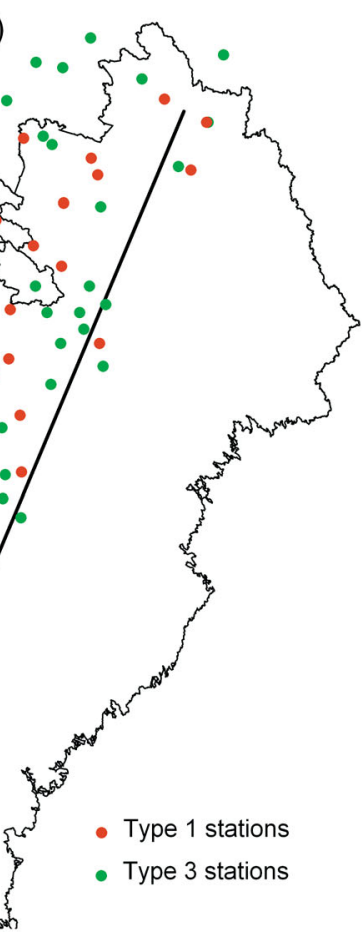

Fig. 1. (a) Mean annual precipitation in the study area (1981 to 1999). (b) Meteorological stations operating during the investigated period (1981 to 1999). Type 1 stations provide real-time data tion on topography, wind speed and wind direction. The purpose of this paper is to evaluate that assumption. The relationship developed by Johansson \& Chen (2003) was used to define a spatial pattern for each precipitation event according to actual wind conditions. To assess the value of wind data in the interpolation procedure, precipitation estimates were also made without the use of wind information. For operational modelling, it is important that an interpolation scheme is applicable in all parts of Sweden. However, the mountainous region in the northwest is of particular interest due to its high runoff and large reservoirs for hydropower production. It is also the most problematic area with respect to precipitation interpolation, due to strong precipitation gradients and a sparse meteorological network (Fig. 1). Consequently, this evaluation focuses on that region.

\section{METHODS AND DATA}

\subsection{Optimal interpolation}

Precipitation $(P)$ data were interpolated using optimal interpolation (Gandin 1965, Daley 1991), a geostatistical method similar to simple kriging with varying local means (e.g. Goovaerts 2000). Several evaluations have favoured geostatistical methods for the interpolation of precipitation (e.g. Creutin \& Obled 1982, Chen et al. 2002). Interpolation is carried out on residuals from a background field $\left(P-P^{m}\right)$ and at the end, the background field $\left(P^{m}\right)$ is added to the interpolated value. The selection of background field is important for the final result and, as it is not known at ungauged locations, it must be modelled.

\subsection{Background field}

Through regression analysis, Johansson \& Chen (2003) established a relationship linking daily precipitation with wind speed, wind direction and topographic variables:

$$
\begin{aligned}
P^{m}= & C_{0}+V \cdot\left(C_{1} \cdot S L_{-} U_{>}+C_{2} \cdot \mathrm{MRF}+C_{3} \cdot S L_{-} D_{>} .\right. \\
& \left.\mathrm{BRF}+C_{4} \cdot S L_{-} U_{>} \cdot \mathrm{CF}+C_{5} \cdot V D I R+C_{6} \cdot U D I R\right)
\end{aligned}
$$

where $C_{0}$ to $C_{6}$ are regression coefficients; $V$ is the wind speed; $S L_{-} U_{>}$is the upwind slope, ascending air (0 for descending air); MRF is the mountain range factor, which varies between 0 and 1 and equals 0 if elevation is more than $250 \mathrm{~m}$ below maximum elevation of upwind mountain range; $S L_{-} D>$ is the downwind slope, ascending air (0 for descending air); BRF is the barrier factor, which varies between 0 and 1 and equals 0 if elevation is more than $250 \mathrm{~m}$ below maximum elevation of upwind barrier; $\mathrm{CF}$ is the coast factor, which decreases from 1 at the coast to zero $40 \mathrm{~km}$ inland in the wind direction; VDIR is the meridional wind component, which varies between 1 and -1 ; and 
UDIR is the zonal wind component, which varies between 1 and -1 .

The definitions of barriers and mountain ranges differ by their extension and their distance to the point of interest. A barrier has a smaller extension, and the upwind distance is less than $50 \mathrm{~km}$. A mountain range lies anywhere between the actual location and the coast in the upwind direction.

The regression relationship can be used to compute a background value for any location and precipitation event. This was the approach in the interpolation scheme using wind information.

To evaluate the effect of wind information, interpolation was also carried out with a background field determined only from geographical parameters. To establish a relationship similar to Eq. (1), stepwise regression was carried out with mean annual precipitation as the dependent variable. Independent variables were the slope in 8 different directions, location and a term accounting for coast convergence. The resulting expression is similar to that used by Häggmark et al. (2000) for Swedish applications, and explains 58\% of the variance in mean annual precipitation:

$$
\begin{aligned}
P^{m}= & C_{0}^{\prime}+C_{1}^{\prime} \cdot X+C_{2}^{\prime} \cdot Y+C_{3}^{\prime} \cdot S_{S} . \\
& \mathrm{MF}+C_{4}^{\prime} \cdot S_{W} \cdot \mathrm{MF}+C_{5}^{\prime} \cdot C V
\end{aligned}
$$

where $C_{0}^{\prime}$ to $C^{\prime}{ }_{5}$ are regression coefficients; $X$ and $Y$ are locations, east-west and south-north, respectively; $S_{S}, S_{W}$ are slopes towards the south and west, respectively; MF is the mountain factor, which varies between 0.3 and 1 and has a similar effect to the barrier factor used in Eq. (1), and reduces the influence of slope for narrow mountain valleys; and $C V$ is a term accounting for coast convergence, directly proportional to the difference in percentage of sea in neighbouring grids.

\subsection{Evaluation of interpolation}

All interpolations were made on daily data, to a gridmesh of $4 \times 4 \mathrm{~km}^{2}$. Catchment precipitation was calculated as the average of the grids covering the catchment. The purpose of the interpolation scheme is to estimate areal precipitation for rainfall-runoff modelling. However, the true areal precipitation is not known, and areal estimates cannot be directly verified against observations. The evaluation thus involved several criteria.

Point estimates were verified against meteorological station data. Jack-knife and cross-validation methods were used for the verification.

In a few mountainous catchments where evapotranspiration is low, long-term mean estimates were verified against runoff through the water balance equation. The calculation is important because it is the only way to verify estimates for high altitudes where no observations are available.

Catchment precipitation estimates were made with 2 sets of meteorological data. The first set included all available stations; the second set only included stations reporting in real time (Type 1 stations). By reducing the number of stations drastically, it was possible to assess the stability of the interpolation scheme and its capability in describing the spatial pattern.

The interpolated precipitation values were used as input to the HBV rainfall-runoff model (Lindström et al. 1997) to investigate the influence on model performance.

\subsection{Data}

Daily precipitation values were available from the national networks covering Sweden and part of Norway. In the study area, 230 stations were operating during the whole or part of the investigated period 1981 to 1999 (Fig. 1). Data were corrected for catch losses using station specific factors with a seasonal variation (Eriksson 1983, Alexandersson 2003). In total, $20 \%$ of the stations were of Type 1 .

The regression relationships in Eqs. (1) \& (2) were developed on data from the whole of Sweden, using stations operating at the same location from 1981 to 1995. A total of 450 such stations were available: 370 were used to develop the regression relationship and 80 were left for independent verification; 70 and 20 were located in the mountainous region, respectively. These 90 stations were used for verification of point estimates, while the complete set of mountain region stations (230) were used to estimate catchment precipitation.

Because it is the large-scale wind that matters for precipitation distribution, the geostrophic wind was used to describe the airflow (Johansson \& Chen 2003). As it is computed from sea level pressure observations, it is also easily available. For this study, we used wind data that were already computed for a $1 \times 1^{\circ}$ grid for 3 hourly intervals (Omstedt et al. 1997). Wind speed and wind direction during precipitation events follow a seasonal pattern. Wind speeds in winter are generally $30 \%$ higher than in summer. Close to the water divide along the Norwegian border, winds from the west dominate precipitation events in winter. Further to the east, most winter precipitation falls when winds are from the south (Fig. 2). In summer, winds from the north and from the east bring most precipitation.

Topographic information was taken from the $50 \times$ $50 \mathrm{~m}^{2}$ elevation database from the National Land Survey of Sweden. It was re-sampled to a $4 \times 4 \mathrm{~km}^{2}$ grid mesh. 


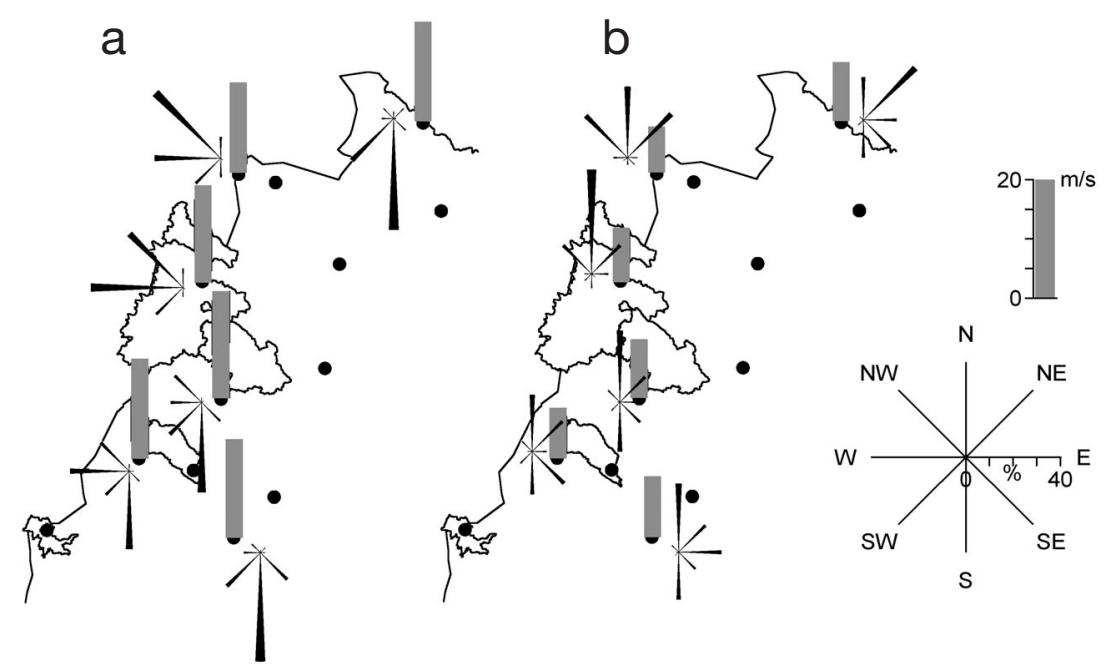

Fig. 2. Wind distribution and average wind speed for precipitation in (a) January and (b) July (geostrophic wind)

\section{RESULTS}

\subsection{Spatial distribution}

The use of wind information has a clear effect on the spatial distribution of the interpolated precipitation, particularly in areas with steep topography (Fig. 3). In winter, it leads to higher precipitation estimates in the most western part and at high altitudes, and to lower precipitation estimates in the mountain valleys. This is in agreement with the high wind speeds which, according to Eq. (1), result in stronger precipitation gradients. It is also in agreement with the dominating westerly winds. In summer, the effects are smaller, but tend to go in the opposite direction with lower precipitation in the western part and at high altitudes and with less strong precipitation gradients. This is the result of low wind speed and more easterly winds.

\subsection{Verification of point estimates}

The 90 stations operating at the same location from 1981 to 1995 were used for the verification of point estimates. First, daily precipitation for this period was estimated for the 20 stations saved for verification purposes, using the other 70 as input to the interpolation (a jackknife approach). Two criteria were used to evaluate the accuracy of the precipitation estimates: (1) the coefficient of determination for daily precipitation, which was computed for each station for the relevant period and then averaged over all stations $\left(\mathrm{r}^{2}\right)$; and (2) the absolute error in the estimated total precipitation, $\left|P-P_{\text {est }}\right| / P$, which was computed for each station for the relevant period. Then the mean error was obtained by averaging errors over all stations. The coefficient of determination describes the similarity in temporal patterns, while the absolute error gives the magnitude of the difference.

There was no difference in the $r^{2}$ value between the 2 different approaches, with and without wind information. In both cases, the value was 0.78. However,
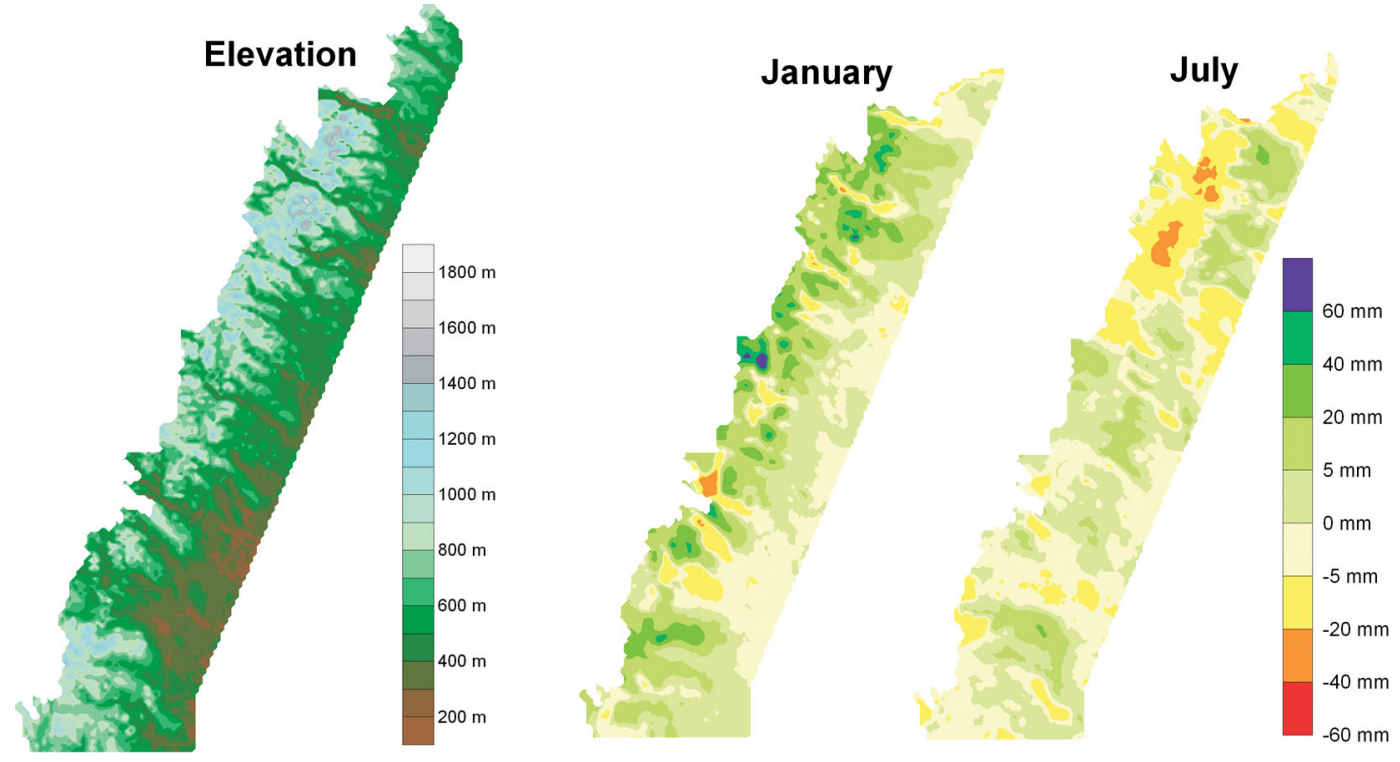

Fig. 3. Difference in mean January and July precipitation between the interpolation schemes with and without wind information. Mean precipitation over the whole area is approximately $90 \mathrm{~mm}$ in January and $110 \mathrm{~mm}$ in July. An elevation map is shown (left) 

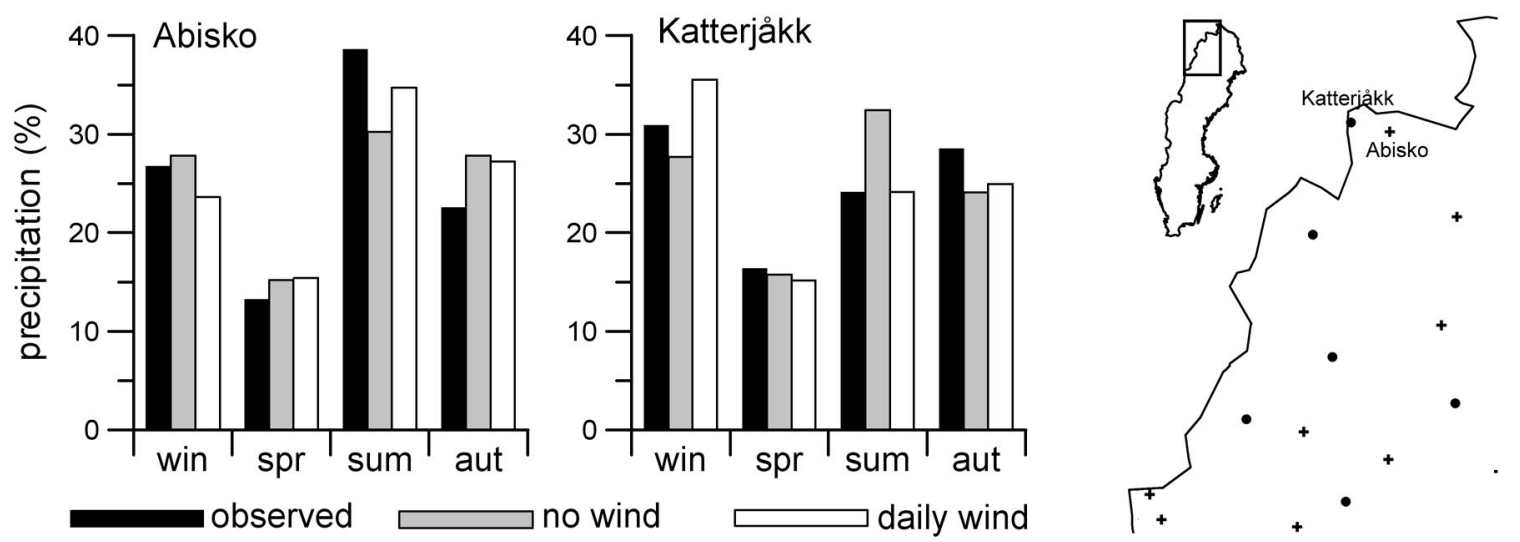

Fig. 4. Cross-validation of point precipitation estimates. Seasonal variation of observed and estimated (no wind and daily wind) precipitation at 2 mountain stations (Abisko and Katterjåkk). Mean values for 1981 to 1995. The interpolation scheme using wind information predicts better the difference in seasonal variation due to station location on different sides of the mountain

the mean error was smaller for the interpolation scheme using wind data, $6.5 \%$ compared to $7.9 \%$ for the other scheme. A sub-division into seasons or single months did not show any systematic deviations from these results.

In a cross-validation between all 90 stations, the main advantage in the use of wind data seemed to lie in the greater capability to predict the difference in seasonal variation along the water divide between Sweden and Norway. In northern Sweden, precipitation generally has a maximum in summer, but furthest to the west the maximum occurs in winter. This shift from winter to summer maximum takes place over a small distance, as demonstrated by 2 stations-Katterjåkk and Abisko - which are only $30 \mathrm{~km}$ apart (Fig. 4). The interpolation scheme using wind information managed to estimate a winter maximum for Katterjåkk and a summer maximum for Abisko, while the scheme without wind gave both stations similar seasonal patterns.

\subsection{Verification of catchment precipitation}

Areal precipitation was estimated for 6 mountainous catchments (Fig. 5) for the period 1981 to 1999. Over long periods, the storage of water within a catchment can be neglected and the water balance equation can be written as:

$$
P=Q+E
$$

where $P$ is the mean precipitation, $Q$ is the mean runoff and $E$ is the mean evapotranspiration.

In northwestern Sweden, evaporation is low in relation to runoff (SNA 1995). Thus, catchment mean precipitation can be verified through the water balance, with a rough estimate of mean evapotranspira-
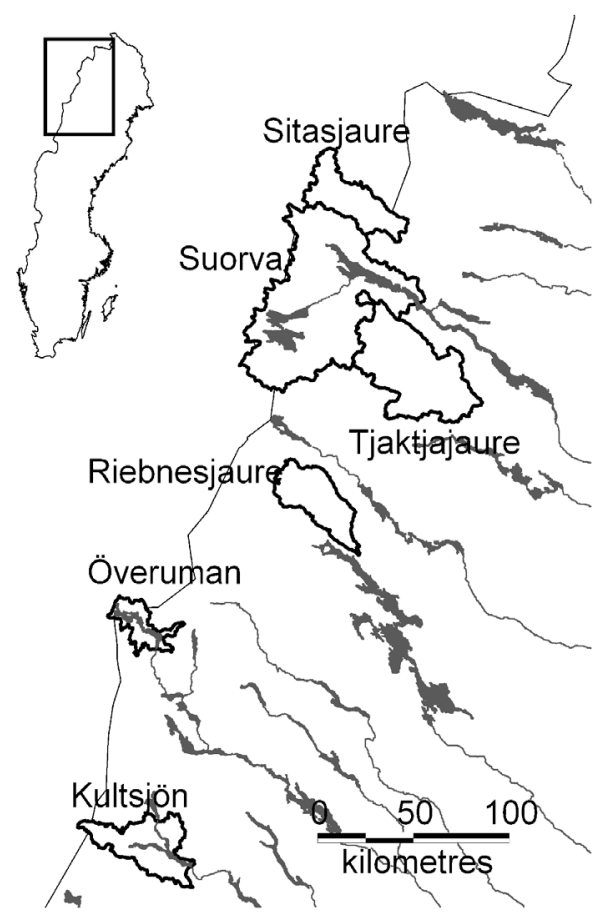

\begin{tabular}{lrccc}
\hline Catchment & $\begin{array}{r}\text { Area } \\
\left(\mathrm{km}^{2}\right)\end{array}$ & $\begin{array}{c}\text { Elevation } \\
\text { range }(\mathrm{m})\end{array}$ & $\begin{array}{c}\text { Runoff } \\
(\mathrm{mm} / \mathrm{yr})\end{array}$ & $\begin{array}{c}\text { Evaporation } \\
(\mathrm{mm} / \mathrm{yr})\end{array}$ \\
\hline Sitasjaure & 978 & $600-1200$ & 1340 & 100 \\
Suorva & 4691 & $400-1300$ & 1080 & 125 \\
Tjaktjajaure & 2250 & $450-2050$ & 875 & 150 \\
Riebnesjaure & 976 & $500-1600$ & 738 & 150 \\
Överuman & 652 & $500-1200$ & 1290 & 125 \\
Kultsjön & 1097 & $550-1300$ & 906 & 150 \\
\hline
\end{tabular}

Fig. 5. Catchments used for verification of precipitation estimates. Mean annual runoff is given for 1981 to 1999. The value for evaporation is a rough estimate 
Table 1. Estimated catchment mean annual precipitation 1981 to 1999. Verification through the water balance. $P$ : mean annual precipitation; $Q$ : mean annual runoff; $E$ : mean annual evapotranspiration

\begin{tabular}{|lrrcr|}
\hline Catchment & \multicolumn{2}{c}{$\begin{array}{c}\text { Precipitation }(\mathrm{mm}) \\
\text { Daily wind }\end{array}$} & \multicolumn{2}{c|}{$P /(Q+E)$} \\
& \multicolumn{2}{c}{ No wind } & \multicolumn{2}{c}{ Daily wind No wind } \\
Sitasjaure & 1320 & 1320 & 0.92 & 0.92 \\
Suorva & 1210 & 1190 & 1.00 & 0.99 \\
Tjaktjajaure & 1120 & 1020 & 1.09 & 1.00 \\
Riebnesjaure & 974 & 927 & 1.10 & 1.04 \\
Överuman & 1280 & 1090 & 0.90 & 0.77 \\
Kultsjön & 1110 & 1040 & 1.05 & 0.98 \\
\hline
\end{tabular}

tion. Long-term mean precipitation estimated from all available stations (Fig. 1) is given in Table 1 together with the ratio $P /(Q+E)$. Ideally, this ratio should be equal to 1 but, due to uncertainties in runoff measurements and evapotranspiration estimates, a perfect fit is not to be expected. In view of this, no clear preference could be given to one interpolation scheme with respect to the long-term mean values. With the exception of Överuman, the ratio $P /(Q+E)$ is within $\pm 10 \%$ of 1.0 for both schemes. In the most western catchments, the seasonal distribution shows a slightly higher winter precipitation and a slightly lower summer precipitation for interpolation with wind data (Fig. 6a).

To test the stability of the interpolation schemes, catchment precipitation was estimated with a reduced number of stations. This is of interest in operational runoff forecasting when a limited number of stations are available for the month preceding the forecast. In the test, only Type 1 stations were used, and this meant a very low station density, particularly around the 2 catchments furthest to the northwest (Suorva and Sitasjaure). For those 2 catchments, the use of wind data gave a greater similarity to the estimates based on all stations. The total precipitation differed less, and the correlation between daily values was higher (Table 2). In addition, the seasonal distribution was better maintained (Fig. 6b). The results indicate that wind information contributes to a better description of the spatial variation between stations and is less sensitive to changes in the meteorological network. The results are similar to those presented by Kyriakidis et al. (2001) in a study from Northern California. They concluded that integration of low-atmosphere and terrain information in a geostatistical framework could lead to more accurate representations of the spatial distribution of rainfall and that the magnitude of the improvement would depend on, among other things, the density of the rainfall stations.
Table 2. Criteria for changes in estimated catchment precipitation when station density is reduced and only Type 1 stations are used. Period is 1981 to $1999 ; \mathrm{r}^{2}$ : coefficient of determination

\begin{tabular}{|lcccc|}
\hline Catchment & \multicolumn{2}{c|}{$\begin{array}{c}\text { Change in total } \\
\text { precipitation (\%) } \\
\text { Daily wind No wind }\end{array}$} & \multicolumn{2}{c|}{$\begin{array}{c}\mathrm{r}^{2} \\
\text { Daily values } \\
\text { Daily wind No wind }\end{array}$} \\
\hline Sitasjaure & 8.3 & -12.9 & 0.83 & 0.72 \\
Suorva & 5.0 & -11.8 & 0.84 & 0.71 \\
\hline
\end{tabular}

\subsection{Runoff modelling}

The HBV rainfall-runoff model (Bergström 1995) was set up for the 6 catchments in Fig. 5. The HBV is a conceptual model, and the parameter values are determined through calibration against observed runoff. In this case, the period September 1, 1982 to August 31, 1992 was selected as the calibration period, and September 1, 1992 to August 31, 1999 as the verification period in a split-sample test. The model was calibrated through an automatic procedure (Lindström 1997), with precipitation input from both interpolation schemes. For the calibration, precipitation estimates based on all available rainfall stations were used. The model performance was evaluated by 2 criteria.

The $\mathrm{R}^{2}$ value (Nash \& Sutcliffe 1970), calculated as:

$$
\mathrm{R}^{2}=1-\frac{\Sigma(Q C-Q R)^{2}}{\Sigma(Q R-\overline{Q R})^{2}}
$$

where $Q C$ is the simulated runoff, $Q R$ is the recorded runoff and $\overline{Q R}$ is the mean recorded runoff.

The volume error (VE), calculated as:

$$
\mathrm{VE}=\frac{\overline{Q C}-\overline{Q R}}{\overline{Q R}}
$$

where $\overline{Q C}$ is the mean simulated runoff.

With respect to the fitness criteria, the 2 catchments Sitasjaure and Suorva stand out, with smaller volume errors for the verification period for the scheme using wind information (Table 3). This is probably due to the lower sensitivity to changes in the meteorological network in combination with the low station density in the northwest. In the interpolation, all available stations were used, meaning that the number and their location varied over time. During the 1990s, part of the Swedish network was automated, which led to many changes in station locations. However, for the calibration period, the model performed equally well with both interpolation schemes. This is in agreement with results reported by Andréassian et al. (2001). Xu \& Vandewiele (1992) found that as long as the time series are homogeneous, systematic errors may be taken care of by calibrating the models against observed runoff. The 


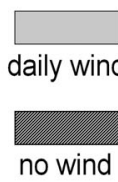

no wind

Fig. 6. Seasonal distribution of estimated precipitation for 3 of the test catchments. Mean values for 1981 to 1999. To facilitate the comparison, the precipitation for the scheme without wind data has been normalised to give the same annual precipitation as the scheme with wind information. Estimates based on (a) all available stations and (b) Type 1 stations (see Fig. 1). After reducing the number of stations, the seasonal pattern is better maintained by the scheme using wind data
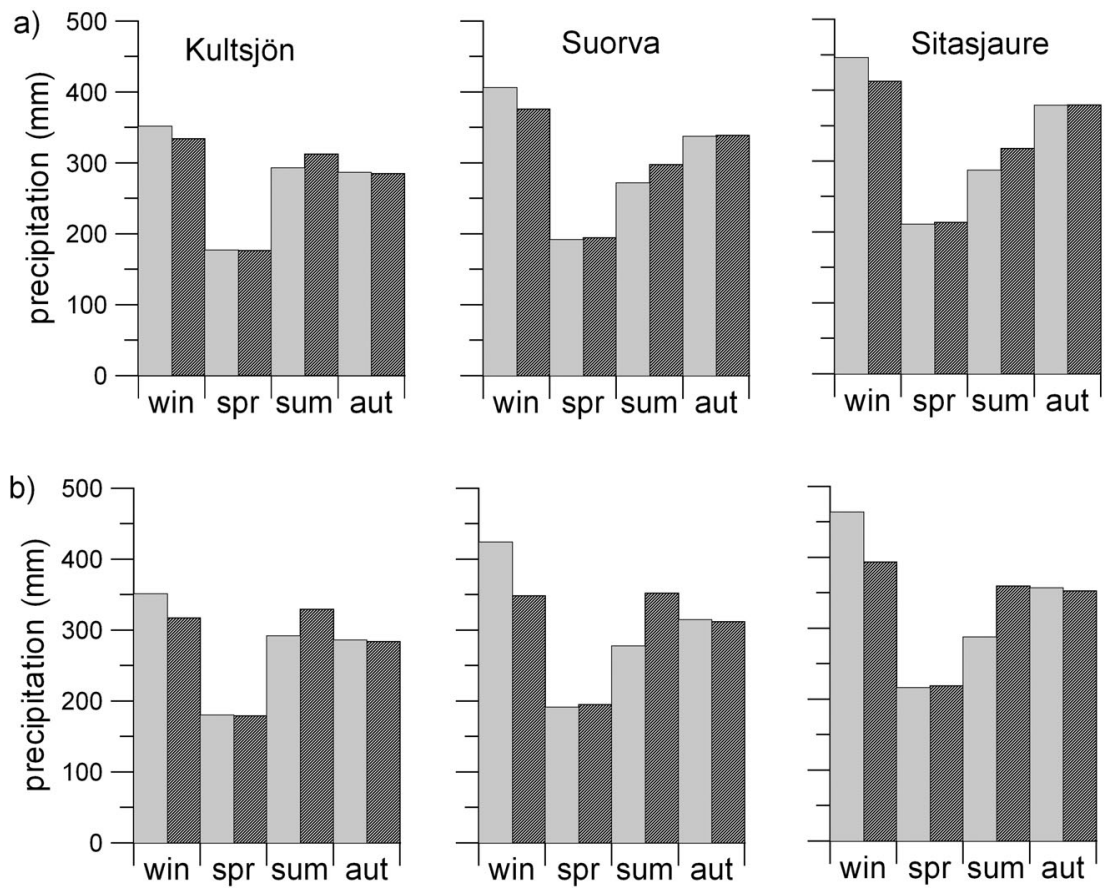

values of the model parameters are then selected in such a way that they adjust the simulated runoff according to the bias in the input data. Several authors have found that the catchment acts as a filter, also in more fully distributed hydrological models than the one used in this study. The primary reason for evaluation of rainfall patterns is then the need to estimate total precipitation accurately; the distribution within the catchment is of little consequence (Obled et al. 1994, Brath et al. 2003). This is probably particularly relevant for the climatic conditions in northern Sweden with long periods of snow accumulation.

To determine the sensitivity of the interpolation schemes to station density, the model was run with input only from Type 1 stations. This was done for the period 1982 to 1992 without recalibrating the model. A

Table 3. Split-sample test for calibrated rainfall-runoff model. Fitness criteria. Calibration period is September 1, 1982 to August 31, 1992. Verification period is September 1, 1992 to August 31, 1999. The automatic calibration routine gives a volume error of 0 for the calibration period

\begin{tabular}{|c|c|c|c|c|c|c|}
\hline \multirow[t]{2}{*}{ Catchment } & \multirow{2}{*}{\multicolumn{2}{|c|}{$\begin{array}{c}\text { Calibration period } \\
\mathrm{R}^{2} \\
\text { Daily wind No wind }\end{array}$}} & \multicolumn{4}{|c|}{$\longrightarrow$ Verification period } \\
\hline & & & \multicolumn{2}{|c|}{$\begin{array}{c}\mathrm{R}^{2} \\
\text { Daily wind No wind }\end{array}$} & \multicolumn{2}{|c|}{$\begin{array}{l}\text { Volume error (\%) } \\
\text { Daily wind No wind }\end{array}$} \\
\hline Sitasjaure & 0.87 & 0.87 & 0.90 & 0.89 & -5.4 & -12 \\
\hline Suorva & 0.92 & 0.92 & 0.91 & 0.91 & -3.8 & -8.3 \\
\hline Tjaktjajaure & 0.87 & 0.88 & 0.86 & 0.86 & -6.8 & -3.7 \\
\hline Riebnesjaure & 0.79 & 0.79 & 0.80 & 0.79 & 4.8 & 4.1 \\
\hline Överuman & 0.80 & 0.81 & 0.73 & 0.74 & 9.7 & 7.6 \\
\hline Kultsjön & 0.88 & 0.88 & 0.87 & 0.88 & -3.9 & -4.3 \\
\hline Mean & 0.86 & 0.86 & 0.84 & 0.84 & $5.7^{\mathrm{a}}$ & $6.7^{\mathrm{a}}$ \\
\hline
\end{tabular}

comparison between the precipitation estimates in this case and the previous estimates showed that the use of wind information led to more stable precipitation estimates in the 2 catchments Sitasjaure and Suorva, both with respect to the total amounts and the temporal variation. This was reflected in the model performance. The deterioration in model performance was more pronounced for the interpolation scheme without wind data (Table 4).

\subsection{Static versus dynamic wind information}

Some of the advantages of using wind information might be achieved without the need for daily wind data. The seasonal and spatial pattern could be described by information on typical wind directions and wind speeds at different locations and in different seasons. This would facilitate operational applications, when geostrophic wind is less easily accessible than precipitation data.

Tests were made for the Sitasjaure and Suorva catchments, which were the most sensitive to the choice of interpolation scheme. In most tests, the interpolation scheme with typical wind produced similar results to the one with daily data. Estimates with all available meteorological stations gave almost the same long- 
term mean values and the same seasonal pattern. With a reduced number of stations, the change in long-term mean values was similar and the seasonal pattern was equally well maintained with typical wind information. However, there was a lower correlation between daily values (Table 5).

Looking at the time series of monthly values, the monthly estimates differed by more than $20 \mathrm{~mm}$ in about $5 \%$ of the months (when the estimates were based on all stations). Those months were all winter months, characterised by an unusually high proportion of westerly and northwesterly winds and by wind speeds higher than normal for that time of the year. This led to higher precipitation in the western part, stronger elevation gradients and a higher total precipitation for the scheme using daily wind information. The largest differences were found for February 1993. A cross-validation for the precipitation stations shows that the scheme using daily wind data on that occasion better described the east-west precipitation gradients (Fig. 7).

\section{SUMMARY AND CONCLUSIONS}

The aim of this study was to investigate if wind information can be used to improve the accuracy of catchment precipitation estimates for rainfall-runoff modelling in a mountainous region of Sweden. Interpolation schemes with and without wind information were evaluated.

The use of wind information had a clear and positive effect on the spatial distribution of the estimated precipitation, particularly in areas with steep topography. In winter, estimated precipitation was higher to the west and at high altitudes, and lower in the mountain valleys. In summer, the effects were the opposite, with lower precipitation in the west and with less strong precipitation gradients.

Cross-validation against station observations showed that the use of wind data gave a better description of the seasonal pattern, particularly along the water divide between Sweden and Norway. In northern Sweden, maximum precipitation is generally in summer, but furthest to the west the maximum occurs in winter. This shift from winter to summer maximum takes place over a small distance and this could not be described with the interpolation scheme without wind data.
For the estimation of catchment precipitation, the main advantage in the use of wind data lay in the greater stability of the estimated time series. The estimated values were less affected by changes in the meteorological network. This was most evident in the 2 test catchments which had the lowest station density in combination with steep precipitation gradients.

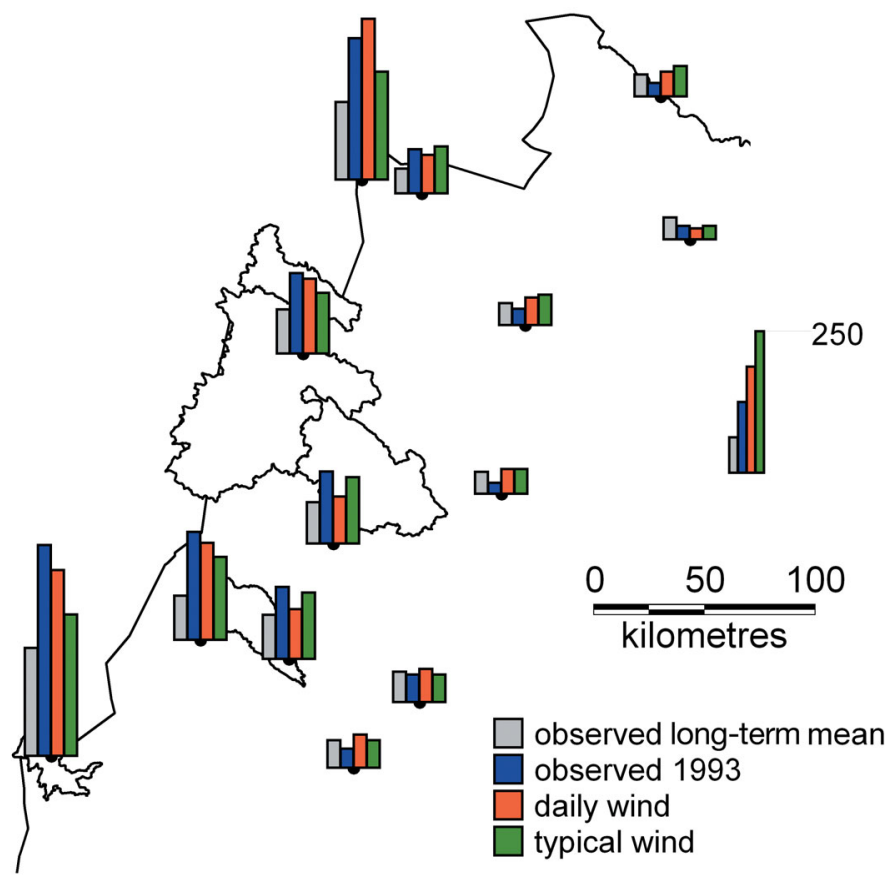

Fig. 7. Cross-validation of station precipitation for February 1993, which was a month with unusually strong westerly and northwesterly winds. Comparison of interpolation schemes using daily wind data and typical wind information, respectively 
For operational applications, one might consider using information on typical wind speed and wind direction at a specific location and time of the year instead of daily wind observations. An interpolation scheme based on typical wind information produced seasonal patterns and total catchment precipitation estimates that are not so different from the ones using daily time series of wind data. It was, however, less capable of reproducing the daily variations when the number of meteorological stations was reduced.

The performance of the HBV rainfall-runoff model was improved by using wind data in the interpolation scheme to determine the catchment precipitation. This is mainly due to the fact that the interpolation using wind data is less sensitive to the locations and density of the stations used. However, the improvement due to the more accurate temporal and spatial distribution in precipitation only had a relatively small effect on the already very high skill of the runoff simulation. This may be due to the filtering effect of the catchment as precipitation is temporarily stored in the snow pack, as soil water or in the lakes.

Acknowledgements. This study could not have been made without the inspiration and support from colleagues at the Swedish Meteorological and Hydrological Institute. Their assistance is gratefully acknowledged.

\section{LITERATURE CITED}

Alexandersson H (2003) Korrektion av nederbörd enligt enkel klimatologisk metodik. (Correction of precipitation with a simple climatological approach. Swedish Meteorological and Hydrological Institute. SMHI Reports Meteorology No. 111 (in Swedish)

Andréassian V, Perrin C, Michel C, Usart-Sanchez I, Lavabre J (2001) Impact of imperfect rainfall knowledge on the efficiency and the parameters of watershed models. J Hydrol 250:206-223

Basist A, Bell GD, Meentemeyer V (1994) Statistical relationships between topography and precipitation patterns. J Clim 7:1305-1315

Bastin G, Loent B, Duqué D, Gevers M (1984) Optimal estimation of the average areal rainfall and optimal selection of rain gauge locations. Water Resour Res 20:463-470

Bergström S (1995) The HBV model. In: Singh VP (ed) Computer models in watershed hydrology. Water Resources Publications, Highland Ranch, CO, p 443-476

Blumer FP, Lang H (1993) Altitudinal dependence of precipitation in the eastern Swiss Alps. In: Sevruk B, Lapin M (eds) Precipitation variability and climate change. Proc Int Symp Precipitation and Evaporation, Bratislava, Slovakia, Vol 2. Swiss Federal Institute of Technology, ETH Zürich, p 141-146

Brath A, Montanari A, Toth E (2003) Analysis of the effects of different scenarios of historical data availability on the calibration of a spatially-distributed hydrological model. J Hydrol 291:232-253

Chen MY, Xie PP, Janowiak JE, Arkin PA (2002) Global land precipitation: a 50-yr monthly analysis based on gauge observations. J Hydromet 3:249-266
Creutin JD, Obled C (1982) Objective analyses and mapping techniques for rainfall fields: an objective comparison. Water Resour Res 18:413-431

Daley R (1991) Atmospheric data analysis. Cambridge University Press, Cambridge

Daly C, Neilson RP, Phillips DL (1994) A statistical-topographic model for mapping climatological precipitation over mountainous terrain. J Appl Meteorol 33:140-158

Eriksson B (1983) Data rörande Sveriges nederbördsklimat. Normalvärden för perioden 1951-80. (Data on the Swedish precipitation climate). Swedish Meteorological and Hydrological Institute. Klimatsektionen Report No. 1983:28 (in Swedish)

Gandin LS (1965) Objective analysis of meteorological fields. Israel Program for Scientific Translations, Jerusalem

Garen DC, Johnson GL, Hanson CL (1994) Mean areal precipitation for daily hydrologic modeling in mountainous regions. Water Resour Bull 30:481-491

Goovaerts P (2000) Geostatistical approaches for incorporating elevation into the spatial interpolation of rainfall. J Hydrol 228:113-129

Häggmark L, Ivarsson KI, Gollvik S, Olofsson PO (2000) Mesan, an operational mesoscale analysis system. Tellus 52A:2-20

Johansson B, Chen D (2003) The influence of wind and topography on precipitation distribution in Sweden: statistical analysis and modelling. Int J Climatol 23:1523-1535

Konrad CE (1996) Relationships between precipitation event types and topography in the Southern Blue Ridge mountains of the southeastern USA. Int J Climatol 16:49-62

Kyriakidis CP, Kim J, Miller NL (2001) Geostatistical mapping of precipitation from rain gauge data using atmospheric and terrain characteristics. J Appl Meteorol 40:1855-1877

Lindström G (1997) A simple automatic calibration routine for the HBV model. Nordic Hydrol 28:153-168

Lindström G, Johansson B, Persson M, Gardelin M, Bergström S (1997) Development and test of the distributed HBV-96 hydrological model. J Hydrol 201:272-288

Nash JE, Sutcliffe V (1970) River flow forecasting through conceptual models. I. A discussion of principles. J Hydrol 10:282-290

Obled C, Wendling J, Beven K (1994) The sensitivity of hydrological models to spatial rainfall patterns: an evaluation using observed data. J Hydrol 159:305-333

Omstedt A, Meuller L, Nyberg L (1997) Interannual, seasonal and regional variations of precipitation and evaporation over the Baltic Sea. Ambio 26:484-492

Phillips DL, Dolph J, Marks D (1992) A comparison of geostatistical procedures for spatial analysis of precipitation in mountainous terrain. Agric For Meteorol 58:119-141

Prudhomme C, Reed DW (1998) Relationships between extreme daily precipitation and topography in a mountainous region: a case study in Scotland. Int J Climatol 18:1439-1453

Shermerhorn VP (1967) Relations between topography and annual precipitation in Western Oregon and Washington. Water Resour Res 3:707-711

Smith RB (1979) The influence of mountains on the atmosphere. Adv Geophys 21:87-229

SNA (1995) Sweden's national atlas: climate, lakes and waters. Raab B, Vedin H (eds). SNA Förlag, Stockholm

Xu CY, Vandewiele GL (1992) Reliability of calibration of a conceptual water balance model: the humid case. In: Russel TF, Ewing RE, Brebbia CA, Gray WG, Pinder GF (eds) Computational methods in water resources IX, Vol 2: Mathematical modeling in water resources. Computational Mechanics Publications, Boston, MA, p 773-780

Submitted: February 9, 2005; Accepted: May 19, 2005

Proofs received from author(s): July 5, 2005 